\title{
A EXPANSÃO DA ESPACIALIDADE URBANA: onde está a área natural?
}

\section{THE EXPANSION OF URBAN SPACE: where is the natural area? RESUMO}

Izes Regina de Oliveira

Arquiteta, mestre e doutoranda em Ciências Ambientais PPGCA Programa de Pósgraduação em Ciências Ambientais. UNESC Universidade do Extremo Sul Catarinense. E-mail izesdeoliveira@hotmail.c om

Teresinha Maria Gonçalves

Profa do Programa de Pós-Graduação em Ciências Ambientais UNESC. E-mail tmg@unesc.net
A integração das áreas naturais ao urbano potencializa as funções ecossistêmicas com melhoria nos fluxos das águas e na vida humana e natural. Com o mundo cada vez mais urbano, é limitante a proteção da biodiversidade e o manejo dos serviços ecossistêmicos. A relação entre espaço construído e espaço natural está cada vez mais distante. No histórico do crescimento das cidades, o presente artigo mostra que o mundo urbano altera gradativamente o uso da terra de agrícola para o assentamento de aglomerações urbanas e vias de acesso. Isso gera vazios urbanos e faz perder a dicotomia urbano-rural. $\mathrm{O}$ aumento previsto da expansão de cidades pequenas e médias até o ano 2030 exige estudos e propostas para supor menores impactos e revitalizar as interfaces entre o urbano e o rural. $\mathrm{O}$ crescimento disperso é real nas cidades e influencia na piora da qualidade de vida, de muitos, e na alteração climática, para todos, além de diminuir a quantidade e qualidade da água. Mais pessoas pressupõem mais impactos e mais água para sobreviver. A cidade de Criciúma, com um perímetro urbano quase na totalidade do seu território e grandes espaços vazios, continua a adensar-se segundo um padrão social segregacionista, desfavorecendo a qualidade de vida para os de menores recursos financeiros. A morfologia característica são os condomínios verticais classe "C" e " $\mathrm{D}$ " distantes do centro urbano e dos serviços e de outro lado os condomínios horizontais fechados de alta classe. O tratamento dos vazios urbanos e a integração entre o ambiente construído e o ambiente natural nas aglomerações poderão aumentar a biodiversidade na escala local e na escala biorregional e deixar a cidade mais resiliente para enfrentar as alterações climáticas.

Palavras-chave: Ecologia urbana. Vazios urbanos. Cidade compacta.

\section{ABSTRACT}

The integration of natural areas into urban areas enhances ecosystem functions with improved water flows and human and natural life. The increasingly urban world is limiting the protection of biodiversity and the management of ecosystem services. The relationship between built space and natural space is increasingly distant. The historical growth of cities shows that the urban world gradually changes the use of agricultural land for the settlement of urban agglomerations and access roads generates more urban voids and loses the urban-rural dichotomy. The expected increase in the expansion of small and medium-sized cities by the year 2030 requires studies and proposals to assume smaller impacts and to revitalize the urban-rural interfaces. The dispersed growth is real in the cities and influences the worsening of the quality of life of many, and in the climatic change, for all, besides diminishing the quantity and quality of the water. More people presuppose more impacts and more water to survive. The city of Criciúma, with an urban perimeter in almost all of its territory and large empty spaces continues to grow according to a segregationist social standard, disfavoring the quality of life for those with lower financial resources. The characteristic morphology is the " $C$ " and " $D$ " class vertical condominiums far from the urban center and services and on the other hand the high class closed horizontal condominiums. The treatment of urban voids and the integration between the built environment and the natural environment in agglomerations could increase biodiversity on the local scale and the bioregional scale and leave the city more resilient to tackle climate change.

Keywords: Urban ecology. Urban voids. Compact city. 


\section{INTRODUÇÃO}

A integração de áreas naturais ao urbano potencializa as funções ecossistêmicas com melhoria nos fluxos das águas e na qualidade de vida de humanos e não humanos, respeitando a natureza. Os impactos das expansões urbanas num mundo cada vez mais urbano limitam a proteção da biodiversidade e o manejo dos serviços ecossistêmicos. Isso influencia na mudança climática e diminui a quantidade e qualidade da água, entre outros problemas, como as inundações e poluição de águas.

O sistema capitalista e o processo de industrialização/urbanização alteram a espacialidade da cidade transformando, deveras, a dicotomia urbano-rural. $\mathrm{O}$ mundo progressivamente mais urbano altera gradativamente o uso da terra em expansões urbanas. $\mathrm{O}$ desenvolvimento dessas expansões cria vazios urbanos e faz perder a percepção da interface entre o urbano e o rural e a espacialidade urbana converte-se em transformações, alterando a paisagem, alterando a ecologia. Essas transformações que intencionam urbanização e desmatam pressupõem fatores capazes de provocar alterações no solo e na bacia hidrográfica, como a impermeabilização, entre outros, que concorre diretamente com o aumento das enchentes.

A partir da crescente urbanização, as análises sobre diferenciação rural-urbano têm se baseado em duas grandes linhas, a dicotomia e o continuum (IBGE, 2017), temas deste artigo. Tratará também da ecologia urbana, que é importante para fazer a ligação física sistêmica entre o ambiente construído e o ambiente natural. Além da ecologia urbana, o ambiente histórico e as culturas tradicionais locais, no pensamento de Leff (2010), são cruciais para a resiliência dos sistemas, por isso devem ser reconhecidos como fonte de sabedoria para a sustentabilidade.

O planejamento tradicional foi incapaz de trazer soluções ou, até pelo contrário, se submeteu aos caprichos econômicos dos empreendedores imobiliários que intensificam a importância dos polos urbanos. Esses excessos marcam a fragmentação do território que, no dizer de Maricato (2015), não deram espaço para o exercício do planejamento territorial, pois têm interesses opostos.

Nesse sentido, o planejamento urbano precisa ser consolidado efetivamente, pelos municípios, pois os problemas triplicarão, visto que o levantamento do Panorama da Biodiversidade nas cidades revela que a expansão urbana deverá triplicar a área urbanizada entre 2000 e 2030 (Figura 1). Esse é um aspecto dos mais transformadores do século XXI (ICLEI, 2012).

A forma de urbanização da cidade brasileira, principalmente após o financiamento do programa MCMV Minha Casa Minha $\mathrm{Vida}^{1}$, confirma povoamentos fragmentados onde as prefeituras não definiram em lei limites expressos da urbanidade. Deixa-se claro que a delimitação oficial da zona urbana e rural é privilégio do município, pela constituição brasileira. Essa é

\footnotetext{
${ }^{1}$ Pela Lei 10.257/2001, da Constituição Federal no artigo 39, todo município faz lei do perímetro urbano.
} 
considerada um instrumento de planejamento urbano, pois pode supor vazios urbanos, dispersão ou compactação.

Figura 1 - Perda de cobertura vegetal nas cidades entre 1900 a 2050

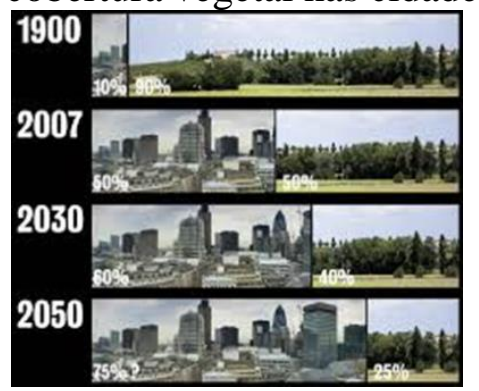

Fonte: LEITE, C. Revista AU edição n. 197, agosto de 2010.

A citada fragmentação do tecido urbano e dispersão dilatam a mancha urbana e distanciam cada vez mais a natureza, diminuindo a diversidade da paisagem. Isso faz a cidade se expandir mais rapidamente que o crescimento das populações urbanas. Ou seja, no urban sprawl-espraiamento das cidades, caracterizado pela expansão horizontal com baixa densidade demográfica. Esse fenômeno impacta mais terras proporcionalmente do que o impacto do aumento da população, pois a alteração do uso do solo com o crescimento da cidade implica significativamente na supressão de ecossistemas. Esse tipo de impacto ameaça a biodiversidade e reduz a resiliência das cidades. Esses fenômenos estão interligados diretamente com a vulnerabilidade e conectados a outras consequências, como carência das condições adequadas de moradia, o consumo exaustivo dos recursos ambientais e a alteração do fluxo das águas.

Dispersões e fragmentações do tecido urbano se dão tanto na expansão horizontal de assentamentos informais, formando favelas e loteamentos irregulares, quanto na expansão dos condomínios fechados, muitas vezes localizados em áreas de preservação ambiental (MC, 2013).

A inter-relação entre o espaço construído, a natureza e o ser humano concentrado nas suas diversas atividades forma o espaço urbano que poderá ser mais ou ser menos urbanizado. A narrativa histórica das cidades que apresentaremos nesta pesquisa possibilitará reconstruir virtualmente a história da urbanização de modo a salientar a relação entre o rural e o urbano e interpretar as principais mudanças ocorridas ao longo dos acontecimentos.

Para acomodar essa população progressivamente urbana da contemporaneidade, as cidades alteraram sobremaneira o ambiente natural a ponto de provocar acidentes e má qualidade de vida. A importância deste artigo está em caracterizar a relação entre ambiente construído e o ambiente natural na interface entre rural e urbano e admitir a hipótese de supor menores impactos nas expansões urbanas, aumentar a resiliência, valorizar a natureza e melhorar a qualidade de vida.

O acréscimo de população urbana prevista pelo Panorama da Biodiversidade justifica este artigo pela necessidade de estudar a alteração da espacialidade urbana, com menor impacto ambiental, 
com menores consequências nas transformações dessas áreas que essa população já habita e para a que habitará nos próximos anos.

O objetivo deste artigo é qualificar a expansão urbana das cidades e buscar o perfil da interface entre o rural e o urbano do município de Criciúma. $\mathrm{O}$ artigo procedeu à revisão da bibliografia à importância dos conceitos morfológicos urbanos no processo de dispersão e interpretação da cidade. Inicia com um recorte na qualificação da tese de doutorado que permeia o assunto, mais especificamente a relação da expansão urbana com o fluxo das águas superficiais do qual se aprofundará no assunto da interface urbano-rural e da expansão urbana e um recorte na dissertação de mestrado com o histórico e evolução urbana de Criciúma. Esta pesquisa é uma sinopse do que tratará a tese de doutorado.

$\mathrm{O}$ artigo se divide em três capítulos, além desta introdução e das considerações finais. $\mathrm{O}$ capítulo 2 traz o histórico da urbanização para interpretar a forma e dispersão urbana na relação da interface rural-urbana ao longo dos acontecimentos históricos mundiais antes e após a industrialização, observando a transformação mais específica de cada época, visando ao aspecto ambiental. No capítulo 3, um marco conceitual, traz diversos autores e conceitos sobre expansão urbana e identifica as consequências da perda da biodiversidade e alteração dos ecossistemas. Na sequência, o histórico da urbanização de Criciúma leva a perceber as dimensões complexas da população em relação à estrutura física para poder confrontar as interfaces rurais e urbanas do desenvolvimento de Criciúma/SC, trazendo exemplos como instrumentos de planejamento, para uso do solo nos grandes espaços vazios. Por fim, a compreensão da cidade contemporânea poderá nortear formas de planejamento urbano, aplicado à sustentabilidade, para a cidade se expandir.

A cidade é feita "das relações entre as medidas de seu espaço e os acontecimentos do passado", mas a cidade não conta seu passado ela o contém, escrito nos ângulos das ruas (CALVINO, 1991, p. 14). A cidade carrega transformações. É nela que a vida acontece e onde se vislumbram ideologias e é dela que partem ideias de modificações, utopias, de projetos que endereçam às "cidades dos desejos", à “cidade celestial”, à “cidade jardim” ou à cidade compacta e sustentável a partir do desejo de mudança.

\section{A EXPANSÃO DA ESPACIALIDADE URBANA - A HISTÓRIA AJUDA INTERPRETAR A MORFOLOGIA DA CIDADE CONTEMPORÂNEA}

Quando a agricultura supera a caça-coleta, o homem nômade se fixa na aldeia. A terra já não mais é compartilhada; a nobreza assume a propriedade particular. Nasce a cidade.

Embora as primeiras cidades tenham aparecido há cerca de 5.500 anos, eram pequenas e rodeadas por uma maioria substancial de gente do campo; e, facilmente, regrediam à 
condição de vilas. As sociedades urbanizadas de hoje, ao contrário, não apenas apresentam aglomerações humanas de dimensões nunca antes atingidas como também tem uma grande proporção de suas populações concentrada nessas aglomerações (DAVIS, 1970, p. 13).

A queda do Império Romano do Ocidente dá início à Idade Média, situada entre os séculos V e XV. A classe nobre começa a se mudar para a cidade, as casas no campo são apenas casas de campo e o poder político é o poder da cidade. A rede de ruas no feudalismo é o resultado de iniciativas particulares, dos habitantes ao construírem suas casas. A unidade territorial básica e política formam a "castelania" com dimensões tais que se pode atravessá-la a pé entre seus limites e voltar no mesmo dia (HOLANDA, 2002). Há completa interação entre o mundo urbano e o rural, claramente opostos, com total equilíbrio entre a paisagem e as atividades agrícolas desenvolvidas, cuja função é produzir alimento para o grupo familiar camponês. Na Figura 2, percebe-se o equilíbrio da paisagem em Céski Krumlov $^{2}$, cidade medieval, tcheca, em cujo planejamento físico, percebe-se a organicidade se adaptar com coerência às realidades. A localização da cidade, em uma ilha fluvial, facilita a defesa contra eventuais ataques. As edificações mais altas permitem um controle visual da região circunvizinha.

Figura 2 - Cidade medieval de Céski Krumlov, República Tcheca

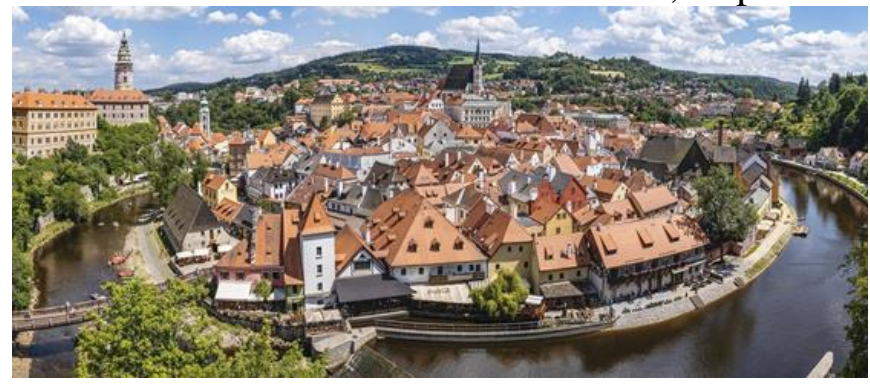

Fonte: Google

O núcleo central, as curvas orgânicas convergentes, o fosso e a muralha dão o caráter da cidade medieval. O final da Idade Média, que vem desgastada da "Idade das Trevas", marca uma divisão de épocas com o Renascimento na vontade de mudar a expressão cultural e filosófica do homem. Teologia e Filosofia estão, agora, separadas e o esteticismo dos séculos XV e XVI conta a história de uma fé em desaparecimento (MUMFORD, 1998). A fé já contrasta com a razão, mas o pensamento ainda é teocêntrico. Na cidade, reúnem-se artesãos que produzem e comerciantes que controlam o comércio.

Com o domínio da navegação e a constituição do comércio, surgem empresas e inicia-se a conquista do mundo. Há ligação comercial entre as cidades por via fluvial e marítima. Muitos autores

\footnotetext{
2 Tombada pelo Patrimônio Histórico da Humanidade.
} 
citam esse momento como início da globalização. Do Novo Mundo, as colônias fornecem matériasprimas, onde novas cidades, na América do Sul, são traçadas.

Da universalidade, do localismo e do absolutismo do Deus medieval, à uniformidade, ao centralismo e ao absolutismo do Estado nacional barroco passaram-se quatro ou cinco séculos entre velhas e novas constelações. De Platão e Vitrúvio ${ }^{3}$ ao Príncipe de Maquiavel aparece a pista de um plano para a nova cidade, e Descartes (1596-1650) reinterpretará o mundo da ciência. Novos urbanistas renascentistas derrubam muralhas e impõem o desenho geométrico no traçado urbano. A derrubada das muralhas começa a dissolver os limites da cidade. As avenidas sacrificam o espaço do cidadão aos caprichos da nova estética urbana. Intervenções com abertura de ruas e praças, de forma cenográfica, simétrica e proporcional estão fora da escala humana. Nesse momento, a arquitetura e a cidade se desatam da natureza. A ideia de progresso enaltece a visão antropocêntrica baseada na autonomia do indivíduo e na razão humana (MUMFORD, 1998; GOITTIA, 1982).

O capitalismo sobrepuja o feudalismo e a revolução da técnica agita a indústria que proporciona modificações no processo de transformação das cidades. Com o grande processo de industrialização, nos séculos XVIII e XIX, por que passa a Inglaterra, como os Estados Unidos, a construção socioespacial das cidades inglesas do século XIX gera um intenso crescimento demográfico e rápida urbanização através do êxodo rural. Engels (1845) aponta a desigualdade entre os bairros operários fétidos, pouco ventilados e escuros e os suntuosos palácios com amplas e iluminadas ruas, por onde circula o "grande mundo" londrino. O palco das discussões sobre a cidade são as aglomerações urbanas. Desaparece a noção de limites, inclusive os limites da expansão urbana. A ideia de centro é modificada pela criação de novas periferias. Está aí a semente da suburbanização. O mundo rural é considerado arcaico, e isso reflete profunda alteração na relação rural X urbano que Ferrão (2000) intitula de complementaridade assimétrica. A nova função rural é fornecer mão de obra desqualificada e barata para as atividades industriais.

Em 1845, Engels se ocupa da história da classe operária, cunhando a expressão "revolução industrial", a qual ele afirma transformar a vida dos tecelões e arruinar famílias que viviam humanamente no campo, agora transformados em máquinas, a serviço da aristocracia. $\mathrm{O}$ autor cita que a concentração de pessoas acompanha o capital e que outras indústrias se avizinham para explorar essa mão de obra. O vilarejo se tona uma pequena cidade, com os trabalhadores e infraestrutura de comunicação e transportes; máquinas e técnicas; o mercado e a bolsa. Por isso, as cidades industriais crescem rapidamente. A concorrência entre a cidade e o campo é o salário mais alto da indústria. Cada distrito industrial na Inglaterra é uma cidade. Nas grandes cidades, onde o comércio e a indústria funcionam bem, ficam mais claras as consequências do proletariado, onde os costumes são

\footnotetext{
${ }^{3}$ Seus estudos foram esquecidos na Idade Média e retomados no barroco.
} 
radicalmente destruídos. Engels coloca os contrastes da realidade urbana, numa indiferença brutal da riqueza da burguesia com a pobreza do proletariado (Figura 3), a multidão das ruas sem capacidade de ser feliz e o egoísmo estreito da classe dominante sem manifestar pudor algum (LEFEBVRE, 1999).

Figura 3 - Rua de bairro pobre de Londres (Dudley Street) gravura de Gustave Doré, de 1872

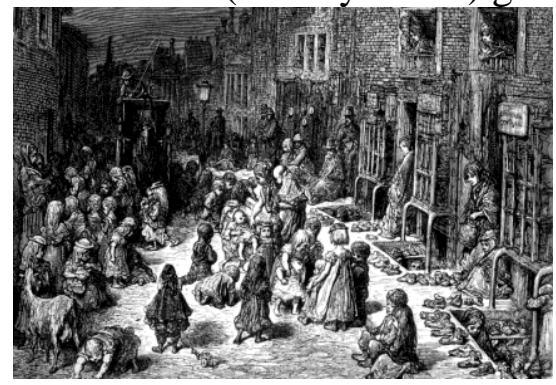

Fonte: Benevolo (1999).

As cidades fabris, propostas urbanas que visaram solucionar ou amenizar essa situação foram a de Robert Owen, construída na Inglaterra, em 1817, e os falanstérios de Charles Fourier, na França (HANNES, 2016). As cidades fabris eram comunidades industriais inspiradas em ideais de vida urbana com alto nível de urbanidade, sem segregação social.

A divisão das fazendas em terrenos prontos para a especulação, intensificação do uso da terra e aumento dos aluguéis era o tipo do planejamento com plantas em grade, ignorando a topografia, aplainando e aterrando. A única função do mundo urbano é atender às necessidades dos negócios, aos crescentes valores dos terrenos e a acelerada expansão. A economia capitalista destrói as características naturais necessárias ao cotidiano humano em rios transformados em esgotos, zonas portuárias apinhadas de mercadorias, árvores sacrificadas, edifícios veneráveis colocados abaixo, um deserto pavimentado. O industrialismo do século XIX produz o mais degradado ambiente urbano, "até mesmo os bairros das classes dominantes eram imundos e congestionados" (MUMFORD, 1998, p. 484). A função do mundo rural é produzir alimento para o grande mercado.

A condição precária da cidade do século XIX faz Ebenezer Howard propor a Cidade-Jardim, responsável em dar respostas aos problemas de superpovoamento das cidades, às precárias condições sanitárias e ao êxodo rural acentuado na Inglaterra, sem separar a sociedade da natureza. A proposta do imã Cidade-Campo que Howard achava plenamente realizável tem objetivo de elevar o nível da saúde e do bem-estar dos moradores. Cada cidade-jardim tem uma população até 30.000 pessoas. Além desse número de pessoas, novas cidades seriam criadas, separadas por um cinturão verde, agrupadas ao redor da cidade central. Todos os benefícios do campo estariam a poucos minutos de caminhada. Da mesma forma, os edifícios públicos, teatro, biblioteca, museus, hospital etc. estariam no centro, com acesso fácil a toda a população (CHOAY, 2015). São vários os princípios de sustentabilidade nessa proposta: o controle do tamanho de cada cidade, a acessibilidade pedestre, o 
transporte coletivo, o uso misto, o reaproveitamento de resíduos sólidos em terras agrícolas e os centros comerciais com economia local.

Em Chicago, há construção de cidade-satélite para frear o crescimento excessivo, Nova York propõe um plano de extensão da cidade, em 1811, e, nos subúrbios ingleses, a presença do verde, nos jardins, marca a baixa densidade populacional, com traçado sinuoso das ruas e casas unifamiliares (HANNES, 2016). Nessa última, uma cópia (malfeita?) da cidade-jardim de Howard. As cidades satélites americanas consolidam o processo de suburbanização após a Segunda Guerra Mundial, com a produção de carros em série por Henry Ford e a construção de estradas. Essa forma de urbanização fica intermediária, numa transição entre o urbano e rural.

A villae suburbanae, em Roma, no século II, símbolo de status, nobreza, riqueza e exclusividade adotada posteriormente nas villas inglesas dos séculos XVII e XVIII, serve de modelo para os futuros subúrbios. Entre os séculos XVIII e início do XX, iniciam as primeiras ocupações suburbanas, consolidadas como local de residência, nas periferias de Londres como Clapham e mesmo com cidades/subúrbios, como Versalhes, próximo de Paris. A urbanização da Paris, de Haussmann, é um processo centralizador com implantação de subúrbios. A urbanização inglesa e norte-americana é um processo descentralizador, um modelo disperso conectado pela via férrea. Mas, no início do século XX, a conexão entre o subúrbio americano e a região urbana central, como citado acima, é por meio do automóvel (MENEZES, 2009). O Brasil e o mundo tiveram influência no processo de suburbanização.

Após a Segunda Guerra Mundial, a industrialização da agricultura transforma o mundo rural em duas realidades distintas. A dicotomia passa a ser pós-rural e urbano com espaço rural bifurcado. De um lado, a diversificação de relações socioeconômica dos centros urbanos com a forte mercantilização da produção agrícola em massa e, de outro, as áreas rurais "profundas" ou "marginais" sem interesse dos citadinos (FERRÃO, 2000).

Nicolescu é um físico teórico que caracteriza a Natureza nas diversas etapas da história, evidenciada pelo grau de desenvolvimento das ciências e das técnicas, pela organização social, arte, religião etc. A Natureza do homem chamado "primitivo", a Natureza dos gregos ou a Natureza da época de Galileu nada tem em comum a não ser o próprio homem. O pensamento mecanicista do século XVIII e XIX concebe a Natureza como máquina (NICOLESCU, 1999). Assim, a urbanização da cidade industrial afronta a Natureza sem preconceito, indiscriminadamente.

A sociedade industrial está de tal forma urbanizada que as aglomerações humanas atingem dimensões nunca antes alcançadas, tão densamente concentradas em proporções que caracterizam uma complexidade social que excedem as comunidades de qualquer outro animal de porte. $\mathrm{O}$ problema não está em determinar a área urbana, mas delinear os limites urbanos (DAVIS, 1970). O 
propósito de a burguesia inglesa morar nos subúrbios, a construção de cidades-satélites americanas, o fordismo e a construção de estradas propiciaram alterar a morfologia da cidade, configurando novas formas de interação de centralidade e periferia e novas relações entre urbano e rural.

\section{A EXPANSÃO URBANA COM SUBURBANIZAÇÃO ESPARRAMADA DEGENERA E A CIDADE COMPACTA PROTEJE O ESPAÇO NATURAL PELA DIMINUIÇÃO DA EXPANSÃO}

Dos fenômenos mais marcantes da expansão urbana da cidade contemporânea é a emergência e a proliferação das gated communities ${ }^{4}$ - assim chamados nos Estados Unidos e na Europa e identificados como condomínios residenciais fechados - no Brasil (Figura 4) e na Argentina. Os espaços públicos tradicionalmente são de uso coletivo. Nos condomínios fechados estes são privatizados. (BIZZIO, 2016). Isso desestrutura a sociedade pois gera espaços segregados e ainda supõe o esvaziamento de equipamentos urbanos que seriam de todos em detrimento de poucos.

Figura 4 - Condomínio residencial fechado Alphaville/SP

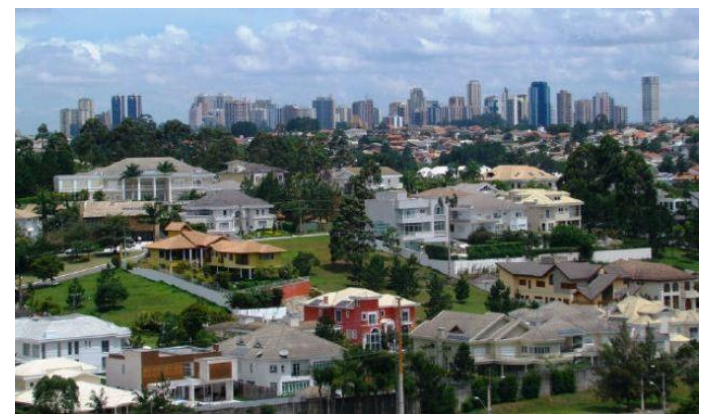

Fonte: https://globalperipheries.wordpress.com/2011/06/30/the-favelas-and-gated-communities-ofsuburban-brazil/. Acesso em: 6 ago. 2018.

As diversas denominações ao modo de crescimento horizontal, espraiamento ou dispersão com baixa densidade, como a suburbanização norte-americana, foram cópias malsucedidas da cidadejardim de Howard. Jane Jacobs (2001) notificou nos anos de 1960 os impactos da suburbanização americana e a segregação espacial. Criticou também as elevadas densidades, alta verticalização e baixa ocupação (400hab/ha) da Ville Radieuse de Le Corbusier - 1933, cujo conceito é oposto ao da cidade-jardim.

No início do século XX, as reformas urbanas de São Paulo, como os projetos do Anhangabaú e Parque Dom Pedro II, e dos bairros Jardins do Pacaembu e Jardim América, tiveram aspiração ao verde urbano (FRANCO, 2008). Esses projetos de suburbanização foram a raiz do paradigma da urbanização dispersa nas cidades brasileiras, espalhando-se pelo Brasil, intensificando a suburbanização e estabelecendo esse como um modelo de expansão urbana.

\footnotetext{
${ }^{4}$ Condomínios fechados.
} 
O Alphaville (Figura 4), o mais famoso bairro periférico, destinado exclusivamente à burguesia, foi inspirado nos ideais da cidade-jardim, mas considera a natureza apenas como bem suscetível de apropriação humana, sem um conceito de preservação da natureza. Esse tipo de expansão urbana caracterizado como urban spraw - espraiamento urbano contínuo - dispersa o crescimento urbano, desfaz a interface entre o urbano e o rural e traz as mesmas consequências da suburbanização americana, impermeabilizações, uso excessivo do automóvel, individualismo, segregação, desmatamento e impermeabilização. Os condomínios fechados se assemelham entre si pela baixa densidade de construção, função única do uso do solo, especialmente pela total separação entre áreas residenciais e aquelas destinadas a comércio e serviços.

$\mathrm{Na}$ interface entre o urbano e o rural, o espaço urbano incorpora a ideia de centralidade ou de periferia (MENEZES, 2009). A periferia caracteriza a dispersão ou o espraiamento. Pelo histórico das cidades, observou-se que a divisão entre o urbano e o rural caracterizou as cidades, na sua origem até o século passado. Hoje, a dualidade parece incompatível com a realidade das cidades atuais. Já não existe a antiga dicotomia rural-urbana. Essa fusão rural-urbano reflete na maioria das cidades contemporâneas, uma vez que a preponderância do território urbano alcança grande parte dos territórios das cidades. Poggi et al. (2015) afirmam que o continuum entre urbano e rural se torna o paradigma do modelo territorial atual e preponderante. Por outro lado, Newman e Jennings (2008) enfatizam a revolução que os movimentos ambientalistas e a sociedade civil fazem por cidades com qualidades humanas e ecológicas, por mais "verde" nas cidades.

$\mathrm{Na}$ suburbanização, as funções exclusivas de uso do solo dificultam a preservação da biodiversidade pelas distâncias para alcançar o centro urbano e seus serviços. A contrariedade que se vê e que assusta ecólogos, biólogos e urbanistas conscientes é a grande quantidade de recursos naturais deteriorados na expansão urbana, descentralizada e dispersa, que altera ecossistemas e seus serviços ${ }^{5}$, prejudicando a vida.

Desvantagens da cidade dispersa:

a) obriga viagens diárias por veículo motorizado individual, uso indiscriminado de combustível fóssil e poluição do ar;

b) construção, instalação e manutenção das redes de infraestrutura - água, coleta de esgotos, drenagem de águas pluviais, iluminação pública, pavimentação ficam mais estendidas. Ou seja, mais longas do que na cidade compacta, porque atravessam áreas desabitadas,

\footnotetext{
${ }^{5}$ È o que a natureza nos dá gratuitamente como tratar da potabilidade e quantidade da água, capturar poluição, armazenar GEE gás de efeito estufa, regular o clima e as mudanças climáticas, prevenir erosão do solo, produzir oxigênio, alimentos, controle de enchentes, oportunizar uma vida mais humana, espiritual, estética, simbólica e o lazer. etc.
} 
portanto, mais caras no custo per capita; os demais serviços de coleta e destinação do lixo, serviços de educação e saúde também, resultam mais caros porque precisam se expandir;

c) o tempo que seria dedicado ao lazer e à família os moradores passa nos transportes;

d) como é baseada no transporte rodoviário, impermeabiliza parte do solo urbano destinado às ruas e aos estacionamentos, impactando o meio ambiente (MARICATO, 2016).

Em oposição, a biodiversidade conservada ativa os serviços dos ecossistemas naturais, já citados.

Outra desvantagem é o custo da pavimentação e da drenagem, que, por sua vez, são as infraestruturas urbanas mais onerosas, responsáveis por 55\% a 60\% do total da infraestrutura urbana mais $20 \%$ dos custos do subsistema energético e os custos do subsistema sanitário detêm aproximadamente $20 \%$. Por outro lado, as vias locais que constituem em mais de $70 \%$ do sistema viário, dependendo do projeto urbano, têm custo menor que as vias estruturais de maior fluxo (DA SILVA, 2016).

A expansão urbana no mundo está ocorrendo não só rapidamente, mas em áreas adjacentes a hotspots ${ }^{6}$ de biodiversidade e em ambientes de água doce com efeitos nocivos sobre a disponibilidade hídrica. Esses impactos ambientais podem ter efeitos nocivos sobre a saúde e bem-estar da população uma vez que da biodiversidade depende a água e o ar limpos, os quais são elementos fundamentais da saúde pública urbana (ICLEI, 2012). Em contrapartida, as cidades dependem de ecossistemas localizados dentro e fora do ambiente urbano para obter os serviços ecossistêmicos ODUM (2004).

Nesse contexto, as realidades atualmente designadas por "áreas urbanas" incluem espaços urbanos, suburbanos, rurais agrícolas e rurais não agrícolas, articulados sistemicamente entre si, às vezes de forma conflituosa (FERRÃO, 2015). É uma confusão. Área legalmente urbana com funções rurais e aglomerações urbanas em área de arredores tipicamente rurais.

\subsection{CIDADE COMPACTA - ALTERNATIVA PARA A EXPANSÃO URBANA RESILIENTE E SUSTENTÁVEL}

Viu-se que o mundo urbano real se encontra na dispersão dos aglomerados humanos que pipocam ao redor do centro urbano, que degenera a vida. De outro lado, estudiosos da cidade "viva" apresentam propostas de interconexão entre espaços construídos e espaços naturais sobre cuja alternativa a cidade e seus habitantes e gestores deverão optar para viver com melhor qualidade.

Reflexões sobre as perspectivas energéticas, ecológicas, sociais e política para o desenvolvimento sustentável do território com base em densidades elevadas e usos diversificados

\footnotetext{
${ }^{6}$ Habitats críticos que têm valor para a conservação da biodiversidade.
} 
num espaço definido permitem maior controle da ocupação de solo e dos consumos de energia e recursos naturais, otimizando a mobilidade e a sociabilidade, entre outras (POGGI et al., 2015).

Autores como Rogers (2001) trazem em Cidades para um pequeno planeta cálculos energéticos e de saúde sobre o quanto os impactos da dispersão se tornam mais dispendiosos em economia e saúde, que a cidade compacta. Para confirmar a eficiência da cidade compacta, Da Silva (2016) lembra que o Brasil ainda tem carência habitacional e compactar possibilita atender a número muito maior de pessoas num mesmo espaço de cidade e de sistemas de infraestrutura redimensionada, otimizando a aplicação de recursos. Cita, ainda, que pensar em cidades dispersas de baixa densidade populacional para o Brasil é incoerente à lógica da sustentabilidade urbana, à justiça social e ao acesso a uma cidade mais barata para todos.

Da Silva et al. (2016) apresentam na Figura 5 cálculos sobre a densidade urbana, confirmando que a cidade compacta além de sustentável é econômica. No estudo, observa-se a importância sobre as decisões de projeto e desenho urbano. Pensar sobre controle da ocupação urbana pressupõe pensar a cidade como um sistema, inter-relacionando todas as dimensões, tratando os temas envolvidos como um todo. Assim, a densidade como um número é muito pouco sobre um assunto tão complexo. Pois, apenas adensar e compactar a cidade contemporânea não a torna sustentável ou economicamente viável. Pelo contrário, poderá até significar impacto e alto custo de urbanização. A conexão entre o ambiente natural e o ambiente construído unido à compactação e adensamento indicarão um caminho sustentável

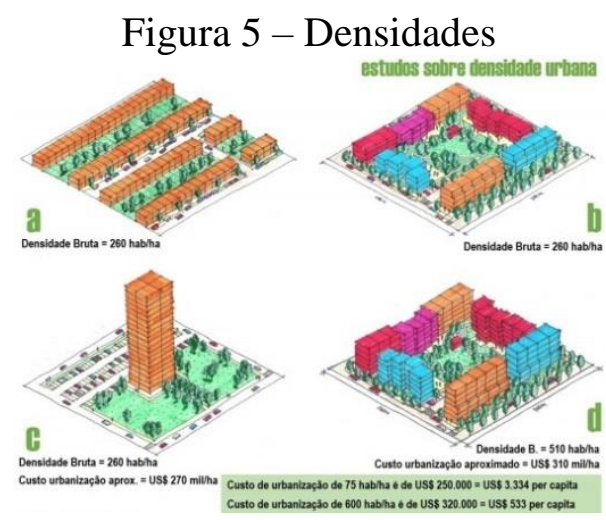

Legenda: Figuras (a) e (b): mesma densidade bruta de 260 hab/ha.

Figuras (c) e (d) quando dobra a densidade, o custo da urbanização diminui. Observe-se que a forma construtiva faz a diferença.

Figura (c) a densidade bruta é de 260 hab/ha, custo aproximado da urbanização US $\$ 270 \mathrm{mil} / \mathrm{ha} \mathrm{e}$ Figura (d) a densidade bruta é de $510 \mathrm{hab} / \mathrm{ha}$, custo aproximado da urbanização US $\$ 310 \mathrm{mil} / \mathrm{ha}$. Cálculos de Urbanização de 75hab/ha de US\$250.000 = US\$3.334/pessoa. Urbanização de 600 hab/ha de US\$320.000 = US\$ 533/pessoa.

Fonte: Da Silva et al. (2016). 
A proposta de Cidade Compacta - Smart Growth ${ }^{7}$-, tutelada por Rogers (2001) e Rueda (2000), está no rol das realidades regeneradoras. Essa é contrária às funções únicas, propõe diversidades de funções de uso e ocupação de solo, potencializando as perspectivas energéticas, sociais e ecológicas.

Seguem as vantagens da cidade compacta indicadas por Rogers (2001):

a) multifuncionalidade do solo, com usos residenciais, comerciais e serviços;

b) facilita a mobilidade pedestre e ciclística, pois reduz deslocamentos;

c) aumenta a sociabilidade entre os habitantes;

d) dá ênfase ao transporte público para alcançar distâncias maiores que mil metros;

e) diminui o uso de combustíveis e emissão de poluentes.

Henrique Peñalosa, prefeito de Bogotá, diz: “Just as fish need to swin, birds to fly, zebras run, we need to walk. Humane cities need to be made for walking"8 (NEWMAN at al., 2008, p. 141).

Cidade compacta, tem usos diversificados num espaço definido, o que diminui o consumo de recursos naturais, pois menos estradas e espaços de estacionamento são necessários. Outros benefícios ecológicos que esse modelo de cidade pode trazer, apontados pelo arquiteto Rogers (2001), é a proteção do ambiente natural pela diminuição da expansão e a inovação na infraestrutura de abastecimento de água. Ademais, a concentração de pessoas e das atividades econômicas e sociais reforça a otimização da infraestrutura existente e diminui o consumo de combustíveis.

A urbanização é um processo inevitável! A expansão urbana é um ciclo que contribui com uma sequência de demandas de estrutura física e serviços e desequilíbrios ecológicos. Nesse contexto, está implícita a discussão entre a cidade compacta, cidade esparramada e cidade densa. Todos os modelos morfológicos necessitam urgentemente ampliar seu estoque de biodiversidade para melhorar os serviços naturais dados pela natureza para combater a mudança climática e podermos continuar vivendo na cidade.

Ao proteger a diversidade ecológica, pode-se criar, por meio de programas, estratégias e técnicas, uma rede de reservas com parques e bosques ligados entre si por corredores ecológicos, que aumentam a diversidade ecológica, do município e biorregião, e mantêm os ecossistemas de apoio e proteção do clima. Essa rede precisa ser suficiente para manter os serviços vitais do ecossistema (NEWMAN et al., 2008; MOLLISON; SLAY, 1994), aumentando a qualidade e quantidade de água, purificando o ar, protegendo o clima, captando gases de efeito estufa (GEE) e suprindo parte das

\footnotetext{
${ }^{7}$ Crescimento inteligente.

${ }^{8}$ Assim como o peixe necessita nadar, os pássaros voar, as zebras correr, nós necessitamos caminhar. Cidades humanas precisam ser feitas para caminhar.
} 
Revista Tecnologia e Ambiente, v. 25, 2019, Criciúma, Santa Catarina/SC ISSN Eletrônico 2358-9426 e ISSN Impresso 1413-8131

necessidades alimentares da comunidade. Muitas cidades ao redor do mundo estão se preparando para melhorar a relação espaço construído X espaço natural.

\subsection{EXEMPLOS DE PROGRAMAS URBANOS QUE COLOCAM BIODIVERSIDADE EM SEU} NÚCLEO

a) Programa $T V A^{9}$ : executado em Belo Horizonte/MG, propõe rede com contribuições socioambientais e econômicas que liga os fluxos de água, o lazer e a ecologia. A união da água, da vegetação e dos espaços públicos previne inundação, oportuniza a recreação e aumenta a biodiversidade, melhorando os serviços ecossistêmicos, tornando a cidade resiliente e prevenindo a alteração climática. Programa semelhante, o australiano water sustainable urban design (WSUD), desenho urbano sensível à água, propõe que a vegetação evapore e absorva a precipitação das águas pluviais, no local, perto de sua fonte, formando uma rede ecológica, usando materiais naturais. Sustentam um regime hidrológico usando técnicas de biorretenção que infiltram, filtram, armazenam;

b) Programa de Telhados Verdes: a Cidade do México visa criar $10 \mathrm{mil} \mathrm{m}^{2}$ de telhados verdes por ano para melhorar a qualidade do ar, regular a umidade, reduzir as temperaturas, proporcionar novos recursos da biodiversidade para a cidade, aumentar a consciência ambiental entre os cidadãos e tem, também, um importante papel educacional (ICLEI, 2012);

c) Agricultura Urbana e periurbana em Cuba: com mais de 54 mil hectares dedicados à produção de frutas e legumes, a apicultura e a pecuária, Havana mantém uma das maiores redes de agricultura urbana do mundo: quatro milhões de toneladas de frutas e legumes são cultivados todos os anos em mais de 200 hortas orgânicas urbanas. A produção de $90 \%$ das frutas e legumes de Havana e a comercialização em feiras locais ajuda a reduzir a pegada de carbono da cidade (ICLEI, 2012);

d) Biocidade de Curitiba: tem planejamento urbano integrado à conservação da biodiversidade. Ações: plantio de espécies de plantas ornamentais e árvores nativas na cidade; estabelecimento de áreas protegidas; revitalização da bacia do rio Barigui para preservar recursos hídricos; e Projeto Linha Verde qualificação do ar e do transporte, por meio de um grande corredor de transporte, com faixas especiais para ciclistas e pedestres, além de um parque linear. O programa iniciado em 2007 executou infraestrutura verde na cidade e aumentou espaços verdes e a qualidade de vida para os cidadãos (ICLEI, 2012);

\footnotetext{
${ }^{9}$ Técnica brasileira que significa Trama Verde e Azul - rede de vegetação e água.
} 
e) Corredores de Crescimento em Melbourne: segunda maior cidade da Austrália, com população maior de quatro milhões de habitantes e previsão de seis milhões nos próximos 30 anos. Órgão independente, está desenvolvendo Planos para Corredores de Crescimento em parceria com conselhos locais, construtores e governo para ajudar a criar comunidades sustentáveis no entorno da moradia, bem atendida por serviços públicos, empregos, transporte, centros urbanos, espaços abertos e infraestrutura básica, considerando os impactos sobre a biodiversidade, integrando a natureza e as pessoas. Novas comunidades devem se beneficiar de plano integrado que proporcione amenidades e caráter próprio que preserve e aumente os atuais valores da biodiversidade. Os planos objetivam reduzir a pegada de carbono e outras pegadas ecológicas. (ICLEI, 2012);

f) suprimento de água, tratamento de esgotos e limpeza ambiental em Cartagena-Colômbia: projeto de 2005 a 2025, reabilita e expande o suprimento de água e tratamento de esgotos, restaura importante área úmida costeira; melhora condições sanitárias e acesso a água limpa para os pobres da cidade. A abordagem inclui a restauração de habitats degradados, proteção de área, avaliação de impactos ambientais cumulativos e o estabelecimento de um painel multidisciplinar de especialistas para supervisionar o processo de planejamento e seleção do local. A integração de atores locais trouxe retorno econômico, estético e ecológico; melhora condições sanitárias e aumenta o valor da terra. O pensamento sistêmico aplicado em Cartagena integra infraestrutura, biodiversidade e comunidades locais que se beneficiam mutuamente na sustentabilidade. (ICLEI, 2012).

\section{HISTÓRICO DA URBANIZAÇÃO DE CRICIÚMA}

As populações das cidades aumentam pelo processo de industrialização/urbanização. Em Criciúma, a urbanização dá início com a exploração do carvão mineral, a partir de 1910, e com a construção da Estrada de Ferro Dona Tereza Cristina, em 1919, quando imigrantes italianos, alemães, poloneses e lusos vindos dos seus países de origem e outros vindos de regiões agrícolas buscam oportunidades de trabalho nas minas de carvão.

A instalação da ferrovia em 1919 e o transporte de carvão e de passageiros, de Criciúma a Laguna, inaugura uma nova era na região. Melhoram as condições de vida e a comunicação. Por outro lado, a cultura tradicional, até então, da agricultura deu seu espaço para os depósitos do rejeito do carvão, o que diminui a diversidade biológica e degrada o ambiente. $\mathrm{O}$ foco é a produção do carvão, como um objetivo único que transmutou em pouca diversidade sociocultural (Figura 6). 


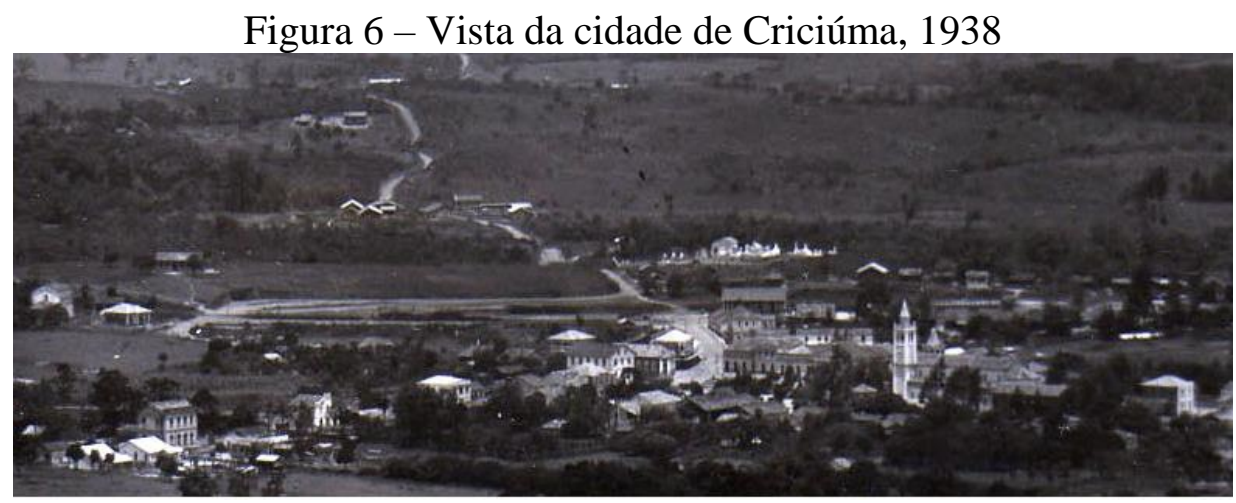

Fonte: Instituto Histórico e Geográfico de Santa Catarina.

A crença, das mineradoras, no progresso material ilimitado, oferece mão de obra abundante. As décadas de 1940 e 1950 duplicam o número de habitantes do município através da migração interna, de êxodo rural intenso dos municípios agrícolas vizinhos para as minas de carvão (VOLPATO, 2001). A necessidade de habitação define a estrutura urbana da cidade e as frentes de expansão urbana aumentam.

Entre as décadas de 1910 a 1960, a Estrada de Ferro Dona Teresa Cristina (EFDTC), na região sul, transporta mais passageiros que as demais ferrovias existentes no Estado. Mesmo assim, a ideia de modernidade associada à de velocidade, conforto e requinte do automóvel prevalece sobre o trem (NASCIMENTO, 2004), e o início da década de 1970 marca a primeira grande reforma urbanística de Criciúma com a substituição dos trilhos da Estrada de Ferro Dona Tereza Cristina pela Avenida do Centenário.

Prosseguindo seu cotidiano de crescimento, a diversificação industrial reflete na transformação urbana rápida e profunda com os investimentos da indústria da construção civil na instalação de conjuntos habitacionais. A forma e a ocupação do espaço urbano são alteradas, tanto no centro urbano quanto nos bairros e na periferia. Na década de 1970, as indústrias localizadas na área urbana e adjacências utilizam 50\% da mão de obra de pessoas com residências fixas nas imediações (VOLPATO, 2001). Inicia-se o transporte chamado pendular ${ }^{10}$ principalmente entre Criciúma e Içara.

\subsection{O PLANO DIRETOR E A EXPANSÃO URBANA EM CRICIÚMA}

A década de 1970 vislumbra um novo modelo de crescimento para guiar o uso do solo e controlar a prosperidade econômica de Criciúma. É, então, aprovado em 1973 o primeiro Plano Diretor (PD), intitulado de Desenvolvimento Integrado de Criciúma. Alterado em 1984 e em 1999 e revisado em 2012 por exigência do Estatuto da Cidade, é um plano físico-territorial, com leis, códigos e índices urbanísticos, sem acompanhamento de políticas de desenvolvimento. Essa revisão

\footnotetext{
${ }^{10}$ Movimento diário de um indivíduo que vai e volta, de casa para o trabalho/estudo, na cidade vizinha.
} 
quantitativa, como as anteriores, não especifica metodologia ou estratégia para o desenvolvimento sustentável.

Pela teoria de planejamento, num plano "físico-territorial", há projeto da cidade para um determinado tempo futuro, com previsão populacional. Como mostra Souza Lopes (2006, p. 123), no plano "físico-territorial" deve estar expressa a preocupação com um conjunto de diretrizes a serem seguidas e metas a serem perseguidas quanto ao uso da terra, ao traçado urbanístico, ao controle da expansão e do adensamento urbanos, à provisão de áreas verdes e ao sistema de circulação. Para o PD aprovado em 2012, não está efetivado um planejamento urbano do que se quer para a cidade, mas foram elencados os dispositivos exigidos pelo Estatuto da Cidade, Lei Federal nº 10.257/ 2001.

A sociedade brasileira não tem a consciência da necessidade de ação planejada sobre as cidades (MARICATO, 1997). Em Criciúma, não é diferente: o Planejamento Urbano é hipotético. Os planos diretores contribuem com índices de aproveitamento, taxa de ocupação, regulamentações, limites de ação do Município, abrangência territorial, mecanismos de gestão e função social da propriedade urbana. As discussões sobre a forma de expansão do crescimento, fluxos da água, dificuldade de água potável, impermeabilização e humanização da cidade ficam a desejar sem o planejamento urbano. Essa afirmativa fica evidenciada nas enchentes, nas correntezas de águas na superfície das ruas, nas ilhas de calor, na má circulação do trânsito, na construção em encostas, na forma da expansão urbana fragmentada. Esse "pecado" não é cometido apenas por Criciúma.

Observando-se o Mapa de Perímetro Urbano - Município de Criciúma (Figura 7), aprovado por meio da Lei $n^{\circ} 3.900 / 99$-, observa-se que a ampliação do perímetro cultivou novos pactos territoriais - no mapa, em laranja, dando ênfase à dispersão da expansão. No mapa, em vermelho, é a área rural e em amarelo, o perímetro anterior a 1999. O território urbano quase dobrou de tamanho com essa lei cujo perímetro urbano equivale "a olho nu", a aproximadamente $80 \%$ do território municipal.

Essa ação ampliou áreas de expansão urbana, entre elas a região da 4. ${ }^{a}$ Linha, hoje região de condomínios fechados. Esse perímetro urbano abrangendo grande parte das áreas rurais deu ao Plano Diretor possibilidades legais de alocar edificações longe do centro urbano e das infraestruturas e serviços e trouxe obrigações e responsabilidades ao poder público. O zoneamento de uso, na época, poderia ultrapassar o perímetro definido com zonas urbanizáveis e projetado para futuras expansões urbanas, em áreas imediatamente anexas às áreas urbanas consolidadas, para que a expansão pudesse usar os serviços e a infraestrutura já existente. O perímetro urbano e o zoneamento são instrumentos eficazes de planejamento. 
Figura 7 - Perímetro Urbano Município de Criciúma - 1999

\section{PERIMETRO URBANO}
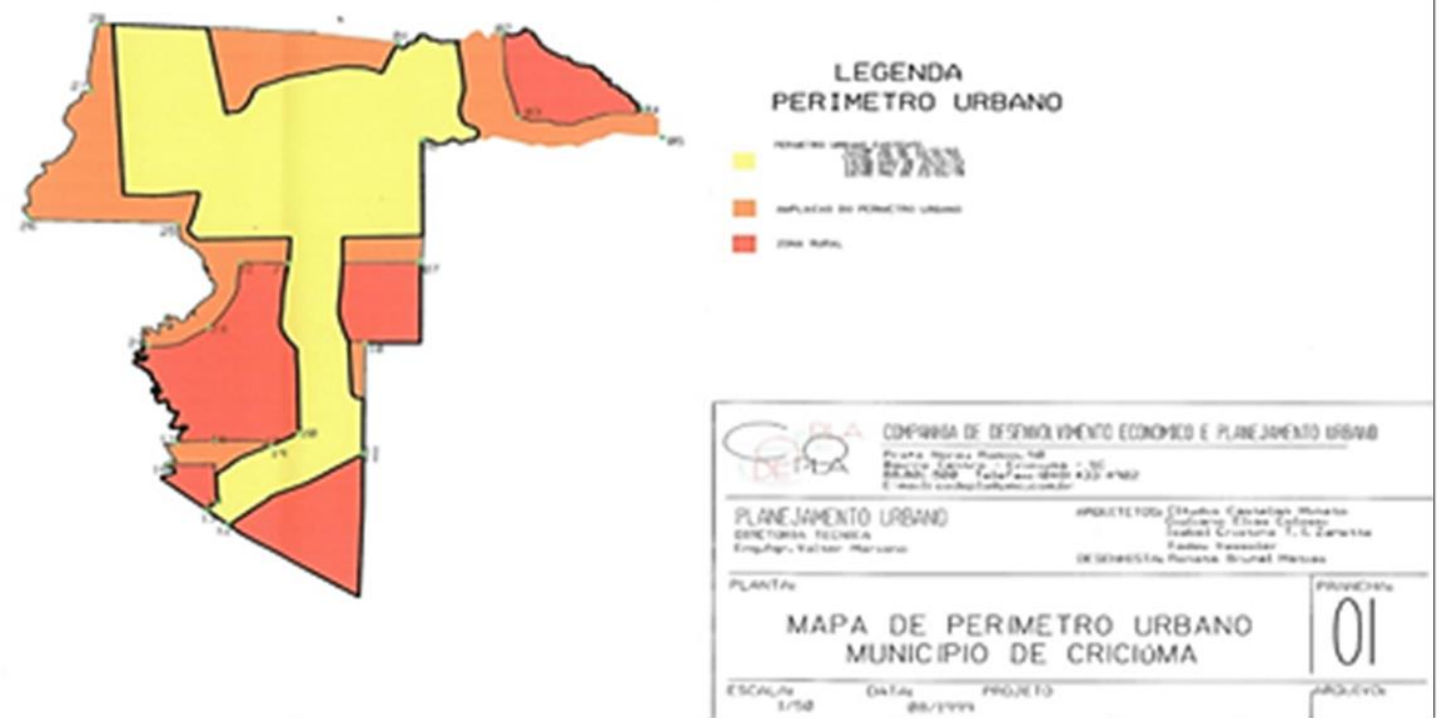

Fonte: Prefeitura Municipal de Criciúma - em vermelho, zona rural.

Trazendo o conceito de planejamento, esse se equipara ao denominado planejamento "regulatório", também chamado planejamento de "facilitação". Souza Lopes (2006) destaca o planejamento "regulatório" ligado aos interesses imediatos do capital privado e subordinado às tendências do mercado. No caso citado, de Criciúma, o Plano Diretor poderia controlar e disciplinar as expansões urbanas, restringindo o perímetro urbano e, consequentemente, diminuindo as forças desse mercado. O objetivo do aumento do perímetro urbano, citado na época, foi angariar impostos aos cofres públicos. Ledo engano! Contribuiu para mais gastos públicos, pois a municipalidade ficou, com essa ação, responsável por aumentar as infraestruturas e expandir os serviços e equipamentos urbanos. Além disso, essa situação de ampliação do perímetro urbano possibilitou a morfologia atual de espraiamento ou dispersão urbana. O perímetro urbano atual sancionado por meio da Lei Complementar $n^{\circ}$ 207/2017 tem poucas alterações, mas, pelo mapa de zoneamento, percebe-se que ampliou as áreas de Proteção ambiental e áreas para agropecuária.

O grande problema apontado nessa situação, tema importante deste artigo, foi o aumento de grandes vazios urbanos, situados entre as aglomerações que são, legalmente, áreas urbanas, mas sem uso ou uso rural, com biodiversidade pobre, suscetível aos eventos da alteração climática.

Existem muitos e importantes estudos sobre os condomínios fechados, citando problemas característicos. Aqui, serão elencados apenas os mais importantes observados em Criciúma, sobre a dispersão de espaços urbanizados:

a) o desmatamento das áreas rurais diminui áreas de agricultura e impacta a biodiversidade; 
b) a baixa densidade dos espaços urbanizados interfere no mundo rural não agrícola afetando reservas naturais, diminuindo a saúde dos serviços ecossistêmicos;

c) a distância do centro urbano acarreta a dependência do transporte e uso indiscriminado dos combustíveis fósseis, provocando poluição e congestionamento do tráfego;

d) a geração de segregação social transforma os espaços, distantes dos serviços, em guetos de insegurança.

Vários desses problemas existem porque os bairros distantes do centro urbano tradicional são incompatíveis com os serviços que apresentam. Ou seja, não existem serviços suficientes nos bairros ou aglomerações urbanas o que exige que habitantes tenham que se deslocar para os centros urbanos afim de poderem exercitar suas atividades ou obrigações.

Criciúma tem outros exemplos de alteração da morfologia urbana que pode ser tema para outros estudos, como a transformação das residências do centro tradicional, nas imediações da Praça do Congresso que gradativamente são substituídas por edifícios para dezenas de famílias. A família original se desloca para a região do Bairro Pio Corrêa ou para Condomínios residenciais fechados. O centro está se condensando sem qualidade, com poucos espaços públicos e poucas áreas naturalizadas. Vimos que só aumentar a densidade não é sustentável, pois, no dizer de Maricato (2016), bairros excessivamente verticalizados, como o centro de Criciúma, combinam periferias amplas e dispersas.

\section{CONSIDERAÇÕES FINAIS}

A ecologia urbana vem contribuir com os profissionais e gestores que tratam da cidade sustentável, pois auxilia nas ligações físicas sistêmicas conectadas nas relações entre si do homem, do espaço natural e do espaço construído, para que efetivamente a cidade tenha vida. As ações dessa disciplina atuam no simbólico, no social, econômico e natural, com instalação de estruturas e sistemas localizados entre o ambiente construído e o ambiente natural, como parques, bosques, corredores verdes, infraestruturas verdes, telhados verdes, agricultura urbana e turismo rural. Essas estruturas verdes podem ajudar a cidade seguir um caminho sustentável com renovação urbana e socioeconômica nos espaços tradicionais, como de cidades que entraram no rol da sustentabilidade.

O tempo em que o mundo rural tinha função específica está ficando para trás. Ou já ficou? Os interstícios entre os espaços urbanizados, com definição de uso para os vazios urbanos, poderiam entrar nos planos diretores com objetivo de conservar ou proteger a natureza. Parques e bosques naturais são áreas que podem ser reconhecidas e, no dizer de Ferrão (2000), em muitos casos já estão sendo, com a função de atividades de turismo e lazer valorizadas nos processos de desenvolvimento sustentável. Já temos visto em Criciúma, na região da estrada do Imigrante, bairro Verdinho, 
considerada pelo PD Criciúma como área de preservação ambiental (APA), muita atividade de lazer e turismo.

O tratamento sobre a dispersão da cidade, no controle dos vazios urbanos enfatizado por Newman e Jennings (2008), é aumentar a biodiversidade não apenas nas escalas locais, como também nas escalas biorregionais, pois o bioma, a comunidade vegetal e animal de uma região, não reconhece limite, indo além da linha imaginária do território municipal.

Assim, vimos que a recuperação da biodiversidade por meio de redes de estruturas verdes reduz impacto aumenta a interação social e comunitária, a graciosidade e a exuberância da vida animal e vegetal, reconduz à qualidade e quantidade de água, melhora a econômica local, pode renovar a cultura, sugerida por Leff (2010), e encoraja a sustentabilidade, tornando possível a resiliência da cidade. Essa é a forma de devolver a conexão entre a cidade, os habitantes e a natureza.

O alento para arquitetos urbanistas é que, segundo o ICLEI (2012), mais de 60\% da área projetada para ser urbana em 2030 ainda estão para ser construídas. Além disso, traz oportunidades sem precedentes para as prefeituras promoverem a sustentabilidade global. Os desenhos urbanos sustentáveis para sistemas com maior eficiência são exemplos que muitos países estão buscando para o uso de recursos vegetais e água, como citado os programas TVA - Trama Verde Azul (verde de vegetação e azul de águas) brasileiro e WSUD - Water Sensitive Urban Design - Desenho Urbano Sensível à Água - sistema australiano entre outros semelhantes, existentes, na Holanda e Reino Unido. A sugestão desenvolvida neste artigo é as cidades serem protetoras responsáveis da biodiversidade e dos serviços ecossistêmicos dentro e fora dos seus limites territoriais. Nesse sentido, Odum (2004) recomenda que cada cidade aprenda a calcular os limites do seu ecossistema.

Criciúma necessita relacionar o ecossistema urbano ao ecossistema natural, quanto à estrutura populacional, fluxos de energia e recursos. Precisa atender à capacitação de espaços públicos ótimos, áreas verdes consolidadas, espaços de interações sociais e modos de transporte mais amenos, como pistas exclusivas para bicicletas e boas calçadas sombreadas para melhorar o caos da mobilidade urbana que está por vir em tempo bem acelerado.

\section{REFERÊNCIAS}

BIZZIO, Michele R.; SOARES ZUINUR, João Carlos. A apropriação do ideário cidade-jardim nos condomínios residenciais fechados brasileiros. Revista Vitruvius arquitextos-urbanismo, ano 17, nov. 2016. Disponível em: <http://www.vitruvius.com.br/revistas/read/arquitextos/17>. Acesso em: 02/ mar. 2018.

CALVINO, Italo. As cidades invisíveis. São Paulo: Companhia das Letras, 1991.

CHOAY, François. O urbanismo: utopias e realidades, uma antologia. São Paulo: Perspectiva, Editora, 2015.

DA SILVA, Giovany Jessé Alexandre; SILVA, Samira Elias da; \& NOME, Carlos Alejandro. Densidade, dispersão e forma urbana: Dimensões e limites da sustentabilidade habitacional. 
Revista Tecnologia e Ambiente, v. 25, 2019, Criciúma, Santa Catarina/SC ISSN Eletrônico 2358-9426 e ISSN Impresso 1413-8131

Arquitextos, ano 16, fev. 2016. Disponível em: <http://www.vitruvius.com.br/revistas/read/arquitextos/16.189/5957>. Acesso: 13 ago. 2018.

DAVIS, Kingsley. A urbanização da humanidade. In: Cidades: a urbanização da humanidade. Rio de Janeiro, Zahar, 1970. P. 13-35.

FERRÃO, João. Relações entre mundo rural e mundo urbano: evolução histórica, situação actual e pistas para o futuro. Scielo - EURE, Santiago, v. 26, n. 78, set. 2000. Disponível em: $<$ https://scielo.conicyt.cl/scielo.php?script=sci_arttext\&pid=S0250-71612000007800006>. Acesso em: 06/agosto/2018

FRANCO, Maria de Assunção Ribeiro. Desenho ambiental: uma introdução à arquitetura da paisagem com o paradigma ecológico. 2. ed. São Paulo: Annablume; Fapesp, 2008.

GOITTIA, Fernando Chueca. Breve história do urbanismo. Lisboa: Editorial Presença, 1982.

HANNES, Evy. Desenho ambiental e forma urbana - O caso do bairro de Riverside. Revista Vitruvius Arquitextos urbanismo, ano 17, set. 2016. Disponível em: <http://www.vitruvius.com.br/revistas/read/arquitextos/17.196/6226>. Acesso em: 15/ jul. 2018. HOLANDA, Frederico de. O espaço de exceção. Brasília: Editora Universidade de Brasília, 2002. ICLEI - Governos Locais pela Sustentabilidade. Panorama da Biodiversidade nas Cidades, Secretariat of the Convention on Biological Diversity. Cities and Biodiversity Outlook. Montreal, 2012.

Disponível

em: $<$ http://sams.iclei.org/fileadmin/user_upload/SAMS/Documents/PUBLICACOES/Livro_panorama _cidades_bio.pdf>. Acesso: 21 abr. 2018.

JACOBS, Jane. Morte e vida de grandes cidades. São Paulo: Martins Fontes, 2000.

LEFF, Edgar. Discursos sustentáveis. São Paulo: Cortez, 2010.

LEFEBVRE, Henry. A cidade do capital. Rio de Janeiro: DP\&A, 1999.

MC - MINISTÉRIO DAS CIDADES. Causas do modelo de expansão urbana. Curso à distância Capacidades. Módulo VII, Urbanização Compacta e Controle de Expansão, 2013.

IBGE. Classificação e caracterização dos espaços rurais e urbanos do Brasil: uma primeira aproximação. IBGE, Coordenação de Geografia. Rio de Janeiro: IBGE, 2017.

IPEA - Instituto de Pesquisa Econômica Aplicada. Verticalização urbana e segregação socioespacial: crise da cidade. Anais do I Circuito de Debates Acadêmicos, 2011. Disponível em: <http://www.ipea.gov.br/code2011/chamada2011/pdf/area7/area7-artigo38.pdf >. Acesso em: 13 ago. 2018.

MARICATO, Ermínia. Os vazios urbanos na cidade de Campo Grande. Prefácio. Observatório de Arquitetura e Urbanismo da UFMS, 2016. Disponível em: <http://observatorio.sites.ufms.br/472/>. Acesso em: 13 ago. 2018.

Para entender a crise urbana. São Paulo: Expressão Popular, 2015.

MENEZES, Lucas Veloso de. Condomínio: status e utopia num subúrbio brasileiro do século XXI. 2009. Dissertação (Mestrado em Arquitetura, área de Planejamento e dinâmicas sócio-territoriais) Escola de Arquitetura da UFMG, Belo Horizonte, 2009. Disponível em: <http://www.bibliotecadigital.ufmg.br/dspace/bitstream/handle/1843/RAAO-

7YHJ2E/condom_nio_status_e_utopia_num_sub_rbio_brasileiro_do_s_culo_xxi_menor.pdf?seque nce $=1 \geq$. Acesso em: 12 ago. 2018.

MOLLISON, Bill; SLAY, Reny Mia. Introdução à permacultura. 2. ed. Austrália: A Tagari Publication, 1994.

MUNFORD, Lewis. A cidade na história: suas origens, transformações e perspectivas. São Paulo: Martins Fontes, 1998.

NASCIMENTO, Dorval do. Ferrovia e carvão: a Ferrovia Tereza Cristina no sul do estado de Santa Catarina. In: GOULART FILHO, Alcides (Org.). Memória e cultura do carvão em Santa Catarina. Florianópolis: Cidade futura, 2004, p. 57.

NEWMAN, Peter; JENNINGS, Isabela. Ecocities as sustainable ecosystems: principles and practices. Island Press: Washington, D.C. 2009.

NICOLESCU, Basarab. O manifesto da transdisciplinaridade. São Paulo: TRIOM, 1999. 
ODUM, Eugene P. Fundamentos de ecologia. Fundação Calouste Gulbenkian: Lisboa, 2004.

POGGI, F.; FIRMINO, A.; AMADO. M. Entre o urbano e o rural: perspectivas energéticas para o desenvolvimento sustentável do território. X congresso da geografia portuguesa - Os Valores da Geografia. Lisboa, 9 a 12 de setembro de 2015. Conference Paper, sept. 2015. Disponível em: <file://C:/Users/User/Downloads/cgp2015.pdf>. Acesso em: 6 ago. 2018.

ROGERS, Richard. Cidades para um pequeno planeta. Barcelona: Gustavo Gilli, 2001.

TVA-TRAMA VERDE AZUL. Relatório de Recomendações para a Gestão Metropolitana da RMBH. VI Conferência Metropolitana de Belo Horizonte, 2017. Disponível em: <http://www.agenciarmbh.mg.gov.br/trama-verde-azul/>. Acesso em: 9 jun. 2018.

VOLPATO, Terezinha Gascho. Vidas marcadas: trabalhadores do carvão. Tubarão: Editora Unisul, 2001.

WSUD - Water Sensitive Urban Design guideline. 2017. Disponível em: $<$ http://www.rms.nsw.gov.au/documents/projects/planning-principles/urban-design/water-sensitiveurban-design-guideline.pdf $>$. Acesso: em: 20/ jun. 2017. 